\title{
PENGELOLAAN LINGKUNGAN HOTEL BERBASIS TRI HITA KARANA DI KAWASAN PARIWISATA SANUR
}

\author{
Ni Putu Massuli Adi ${ }^{1 *}$, Wayan Suarna ${ }^{2)}$, Wayan Windiaa ${ }^{3)}$ \\ ${ }^{1)}$ Program Magister Imu Lingkungan, Univ.Udayana. \\ ${ }^{2)}$ Fakultas Peternakan Univ.Udayana. \\ 3)Fakultas Pertanian Univ. Udayana. \\ ${ }^{*}$ Email : putumassuliadi@yahoo.com
}

\begin{abstract}
In the rapid development process, environmental problem has currently become a global issue. Natural environment is very important for people as the subject to development. The protest, friction, and conflict that are now happening in the development process is being caused by the people feel pushed in terms of social, economic, as well as environmental aspects. Some expert said that the development of hotels in Bali have been destroyed the enviroment.

It should be noted that the development in Bali is hoped has currently been stressed in harmony. This is reflected in a Vision of Bali Development 2006-2026, that is: towards Bali Dwipa Jaya based on Tri Hita Karana. Its essence is the development of Bali expected to lead to the prosperity and welfare of the community. In the process for that purpose, however, should be based on the principles of harmony and togetherness, according nature of the concept of Tri Hita Karana (THK). Therefore, it is needed a research on environmental management based on THK in the hotels in Bali, including hotels within Sanur area. The implementation of THK will get harmony at subak, traditional villege, and hotels.

The main objectives of this study are: developing criteria for the hotels based on THK, and to know the level of THK application in hotels within Sanur tourism region. Location of study was determined by purposive way. All hotels listed in Sanur Tourism Regions were selected as research subject. It means that it is done a census method. The respondents of the study are the management of each hotel.

It was found that, the indicator of hotels based on THK could be seen from the three elements, namely parhyangan, pawongan, and palemahan. The elements of parhyangan indicator are: the existence of the temple in the hotel; management of the temple; implementation of ritual ceremony in the temple; maintenance of the temple; implementation of religious speech; and provide assistances to the temples in the vicinity of the hotel. Elements of pawongan indicator are: the harmony between the management and employees; presence of Letter of Working Agreement; harmony between the hotel and surrounding communities; and the number of employees supporting the local culture (Bali). Elements of palemahan inicator are: Green Open Space (RTH); garden park in the hotel area; wastewater management; waste management; emissions management; environmental management; Toxic Hazardous Materials management (B3); construction with typical Balinese; and utilization of CSR for greening activities.

The score of THK application on hotels within Sanur Tourism Region is 79.2\% (good). The application of each element of THK shown that parhyangan element score is $78.7 \%$ (good), pawongan element score is $87 \%$ (very good), and the palemahan element score is $73.6 \%$ (good). The criteria of good implementation of THK at the hotels, indicate through good implementation of all elements of THK and also the score of THK must also at good category.

The indicator of hotel based on THK could be likely developed in the future, and continued to be tested in wider tourism areas, in order to get a standard criterion. Therefore, it will be used as a fundamental guide in assessing the application of THK in the hotels scattered in Bali, and possibly also in Indonesia. Meanwhile, the very high score of application of THK is only found in pawongan element. It thus the all element of THK should be developed in order to improve the environmental management of the hotel in Sanur Tourism Region.
\end{abstract}

Keywords: hote; Application of Tri Hita Karan; Sanur Tourism Region; developmnet vision 


\section{PENDAHULUAN}

Saat ini masalah lingkungan telah menjadi isu global, di tengah-tengah proses pembangunan yang berjalan pesat. Lingkungan alam, sangat penting bagi manusia yang menjadi subyek pembangunan. Protes, friksi, dan konflik yang kini terjadi dalam proses pembangunan, karena manusia merasa telah terdesak secara sosial, ekonomi, dan juga lingkungan. Dampak lingkungan, bisa menyebabkan kehidupan manusia menjadi tidak sehat, terdesak, dan tidak mendapatkan manfaat yang wajar dari proses pembangunan di kawasannya. Hal itu disebabkan karena umat manusia saat ini bersifat sangat teknologis. Manusia yang teknologis adalah manusia yang eksploratif dan eksploitatif, yakni manusia yang selalu berusaha untuk menggali, menikmati, dan kemudian membuang (Windia, 2002). Hal itulah menyebabkan, dalam Kode Etik Pariwisata Dunia, yang diterbitkan oleh UN-WTO, masalah lingkungan sangat banyak disinggung dan ditekankan untuk diselamatkan. Kalau tokh lingkungan harus dimanfaatkan, maka harus bermanfaat bagi masyarakat lokal.

Di Bali, saat ini pembangunan hotel sebagai infrastruktur pariwisata, telah berkembang dengan sangat pesat. Meski sudah ada wacana untuk mengadakan moratorium, namun wacana itu belum menjadi ketetapan pemerintah. Akhirnya, masih dapat disaksikan pembangunan berbagai hotel di kawasan Bali Selatan. Bappeda Bali (2013) mencatat bahwa pembangunan kamar hotel berbintang telah berkembang dari 19.968 kamar pada tahun 2007 menjadi 39.016 kamar, pada tahun 2012. Perkembangannya rata-rata mencapai 9,8 persen per tahun. Angka itu belum termasuk hotel melati, pondok wisata, dan vila.

Pembangunan, khususnya pembangunan hotel, selalu membawa dampak positif dan juga negatif. Pembangunan hotel dapat memberikan dampak penambahan lapangan kerja, dan penambahan pendapatan asli daerah. Tetapi sebaliknya, dapatjuga memberikan dampak pencemaran lingkungan alam, friksi dan konflik sosial dengan masyarakat sekitarnya yang merasa tidak mendapatkan manfaat. Oleh karenanya, dampak negatif tersebut harus mampu dikendalikan.

Sementara itu, patut dicatat bahwa pembangunan di Bali telah menekankan pada harmoni. Hal ini tercermin pada Visi Pembangunan Provinsi Bali tahun 2006-2026 yakni : Menuju Bali Dwipa Jaya yang Berlandaskan Tri Hita Karana. Esensinya adalah bahwa pembangunan Bali memang diharapkan akan menuju pada kemakmuran dan kesejahteraan masyarakat. Namun dalam proses untuk tujuan itu, haruslah dilandaskan pada prinsip harmoni dan kebersamaan, sesuai hakekat konsep Tri Hita Karana.
Selama ini, lembaga yang telah menerapkan konsep Tri Hita Karana (THK) di Bali adalah lembaga subak dan desa adat. Kedua lembaga sosial ini (1) menerapkan konsep Parhyangan (harmoni antara manusia dengan Tuhan Yang Maha Esa), dengan membangun pura, di tempat mana masyarakat melakukan kegiatan hubungan harmoni antara manusia dengan penciptanya, yakni Tuhan YME. Hal itu dilaksanakan dengan berbagai kegiatan upacara keagamaan. (2) Menerapkan konsep Pawongan (harmoni antara manusia dengan manusia), dengan membuat awig-awig. Hal ini dilaksanakan agar masyarakat mengetahui, apa-apa yang boleh dan tak boleh dilakukannya. Dengan demikian diharapkan akan terjadi harmoni antar manusia dalam masyarakat tersebut. (3) Menerapkan konsep Palemahan (harmoni antara manusia dengan alam), dengan tidak merusak alam dalam pembangunan sawah di kawasan subak. Sementara itu, di desa adat, dilaksanakan pembangunan berdasarkan konsep Tri Mandala. Dalam kaitan tersebut, maka kedua lembaga adat ini dikenal sebagai penopang dari proses pembangunan di Bali (Windia dan Dewi, 2011).

Seiring dengan penerapan THK pada lembaga tradisional subak dan desa adat di Bali, maka hotel yang kini banyak dibangun di Bali, diharapkan juga menerapkan THK. Karena pembangunan hotel dalam proses pembangunan kepariwisataan di Bali memiliki dampak yang sangat besar. Hotel juga memanfaatkan sumberdaya (modal, manusia, dan alam) yang sangat besar. Bappeda Bali (2013) mencatat bahwa sumbangan bisnis hotel, pada PDRB Bali terus meningkat. Tahun 2009 tercatat 29,64 \% dan tahun 2012 tercatat 30,66 \%. Artinya, rata-rata meningkat $0,34 \%$ per tahun. Peningkatan itu, tercatat paling tinggi dibandingkan sektor-sektor lainnya. Tercatat juga secara keseluruhan, pada tahun 2009 sumbangan sektor tersier pada PDRB Bali adalah 64,27\%, dan pada tahun 2012 agak menurun menjadi $64,14 \%$. Sementara itu sektor primer pada tahun 2009 sebesar $19,43 \%$, turun menjadi $17,95 \%$. Sektor sekunder yang meningkat dari $11,22 \%$ menjadi $17,84 \%$.

Kalau peningkatan yang tinggi itu tidak diimbangi dengan penerapan harmoni dan kebersamaan (internal dan eksternal), maka akan bisa menimbulkan friksi dan konflik. Bila hal itu terjadi, maka citra Bali sebagai daerah tujuan wisata dunia akan rusak. Hal itu tidak saja merugikan kalangan komponen pariwisata, namun juga bisa menggoncangkan komponen ekonomi masyarakat Bali.

Tantangan proses pembangunan di Bali ke depan tampaknya sangat beragam, baik dari internal masyarakat Bali, maupun tantangan eksternal yang berasal dari luar alam Pulau Bali. Tantangan internal adalah bahwa masyarakat Bali tampaknya 
semakin individualistis, dan materialistis, sebagai akibat dari proses globalisasi. Mereka cendrung tidak memperhatikan kelestarian lingkungan alam, karena mereka sibuk mengejar keuntungan, efesiensi, dan produktivitas. Hal ini tercermin dari tidak diperhatikannya berbagai peraturan yang berkait dengan pelestarian lingkungan (misalnya, tentang sempadan pantai dan jurang, dan jalur hijau). Untuk tantangan eksternal, tercermin dari adanya migran dan wisatawan yang membanjiri Pulau Bali. Kalau mereka sulit melakukan adaptasi dengan budaya Bali, maka akan bisa terjadi berbagai konflik sosial.

Oleh karenanya, perlu ada penelitian tentang pengelolaan lingkungan yang berlandaskan THK pada hotel-hotel di Bali, termasuk hotel di kawasan Sanur. Sebagaimana diketahui bahwa kawasan Sanur adalah kawasan wisata yang tertua di Bali, sebelum akhirnya berkembang kawasan wisata Kuta, Nusa Dua, dan lain-lain. Dengan demikian diharapkan akan dapat dinilai hotel-hotel dengan kriteria pengelolaan lingkungan yang representatif sesuai landasan THK, kriteria hotel yang mengelola lingkungan berbasis THK, dan akan diketahui daftar kondisi hotel dengan tingkat penerapan THK, di Kawasan Pariwisata Sanur.

\section{METODE}

\subsection{Lokasi Penelitian}

Penelitian dilaksanakan di Kawasan Pariwisata Sanur. Penentuan lokasi penelitian dilaksanakan dengan cara purposive. Penentuan lokasi penelitian dengan cara purposive adalah penentuan lokasi dengan alasan/tujuan tertentu. Alasan penentuan lokasi penelitian di Kawasan Wisata Sanur, karena kawasan wisata ini adalah merupakan kawasan wisata tertua di Bali. Kawasan wisata ini terus berkembang, seirama dengan perkembangan kepariwisataan di Bali. Disamping itu, di Kawasan Wisata Sanur, telah dibangun berbagai jenis standar hotel, mulai dari hotel melati hingga hotel berbintang lima. Hotel yang diambil sebagai sampel adalah hotel yang sudah memiliki ijin. Selanjutnya, sebagai responden dalam penelitian ini adalah manajemen hotel yang bersangkutan. Mereka diminta untuk menjawab berbagai pertanyaan yang dituliskan dalam daftar pertanyaan. Jumlah sampel sebanyak 23 buah (sensus).

\subsection{Ruang Lingkup Penelitian}

Ruang lingkup yang diteliti adalah tentang sejauh mana hotel menerapkan konsep Tri Hita Karana (THK). Dengan demikian akan diketahui sejauh mana, suatu lingkungan hotel yang berbasis THK tersebut. Variabel dan cara pengukurannya dalam bentuk indikator, dan skala ukur. Skala pengukuran dari data yang dikumpulkan digunakan nilai skor dengan skala berjenjang. Bentuk daftar pertanyaan yang digunakan adalah tertutup. Di mana diajukan pertanyaan tertutup yang jawabannya harus dipilih oleh responden, berdasarkan pilihan yang disediakan. Skala skor yang digunakan adalah mulai dari skala 1 hingga skala 5 , dengan penentuan interval kelas sebagai berikut.

a. Jawaban yang sangat tidak sesuai, diberkan skor 1.

b. Jawaban yang tidak sesuai, diberikan skor 2 .

c. Jawaban yang sedang/cukup, diberikan skor 3 .

d. Jawaban yang sesuai, diberikan skor 4 .

e. Jawaban yang sangat sesuai, diberikan skor 5 .

Berdasarkan pada praktek skala berjenjang (lima jenjang) atau Likert (Purbaya dan Saputra, 2009), maka didapatkan penentuan selang kelas, skor maksimal yang dapat dicapai adalah $100 \%$ dan skor minimal adalah $20 \%$. Berdasarkan penentuan selang kelas tersebut, maka didapatlah kategori dari hotel tersebut, dalam konteks penerapan THK, seperti terlihat pada Tabel 1.

Tabel 1. Kategori skor penerapan THK, pada hotel di Kawasan Wisata Sanur, tahun 2014.

\begin{tabular}{ccc}
\hline No. & Pencapaian skor (\%) & Kategori \\
\hline 1. & 20 s.d. 36 & Sangat tidak baik \\
2. & $>36$ s.d. 52 & Tidak baik \\
3. & $>52$ s.d. 68 & Cukup/Sedang \\
4. & $>68$ s.d. 84 & Baik \\
5. & $>84$ s.d. 100 & Sangat baik. \\
\hline
\end{tabular}

\subsection{Metode Analisis}

Metode analisis yang digunakan dalam menganalisis data penelitian ini adalah metode analisis deskriptifkualitatif. Sebelum dilaksanakan penelitian lapangan dan hasilnya di analisis, maka alat yang digunakan dalam penelitian itu, yakni berupa daftar pertanyaan, diuji dulu kesahihannya (validitasnya), dan juga kehandalannya (reliabilitasnya).

\section{HASIL DAN PEMBAHASAN}

\subsection{Karakteristik Sampel}

Adapun yang menjadi unit analisis dalam penelitian ini adalah hotel yang bersangkutan. Namun dalam menjawab pertanyaan diwakili oleh pihak manajemen. Oleh karenanya, dalam penelitian ini yang dikategorikan sebagai karakteristik sampel diantaranya adalah : luas hotel, jumlah karyawan hotel, dan tahun operasional hotel. Diharapkan dengan mengetahui data tersebut, akan dapat diketahui data internal dari hotel tsb. Pengetahuan tentang data internal adalah penting untuk mengetahui kondisi faktor internal hotel, dalam 
menunjang kinerja hotel, berkait dengan pengelolaan lingkungannya. Adapun rincian karakteristik sampel, dapat dilihat pada Tabel 2. membutuhkan tenaga. Dengan demikian pihak lakilaki harus mengambil porsi yang lebih besar dalam pelaksanaan pekerjaan di hotel. Adapun hotel yang

Tabel 2. Karakteristik Sampel.

\begin{tabular}{|c|c|c|c|c|c|c|c|}
\hline \multirow[t]{2}{*}{ No. } & \multirow[t]{2}{*}{ Nama Hotel } & \multirow[t]{2}{*}{ Luas Hotel (ha) } & \multicolumn{3}{|c|}{ Jumlah Karyawan (orang) } & \multirow{2}{*}{$\begin{array}{l}\text { Tahun } \\
\text { Operasional }\end{array}$} & \multirow[t]{2}{*}{ Ket } \\
\hline & & & Laki-Laki & Perempuan & Jumlah & & \\
\hline 1. & Inna Sindhu Beach & 1,30 & 61 & 21 & 82 & 1956 & \\
\hline 2 & Tanjung Sari & 1,50 & 73 & 38 & 111 & 1962 & \\
\hline 3 & Tamu Kami & 0,30 & 26 & 20 & 46 & 2000 & \\
\hline 4 & Gazebo & 1,03 & 34 & 12 & 56 & 1972 & \\
\hline 5 & Besakih Beach & 1,25 & 70 & 23 & 93 & 1977 & \\
\hline 6 & Sanur Paradise Plaza Hotel \& Suites & 2,06 & 306 & 77 & 383 & 1996 & \\
\hline 7 & Diwangkara Holiday Villa & 0,51 & 23 & 20 & 43 & 2003 & \\
\hline 8 & Griya Santrian & 1,40 & 199 & 53 & 252 & 1971 & \\
\hline 9 & Peneda View Hotel & 1,00 & 30 & 12 & 42 & 1987 & \\
\hline 10 & Puri Dalem & 0,67 & 36 & 9 & 45 & 1998 & \\
\hline 11 & Sativa Sanur Cottages & 0,05 & 45 & 13 & 58 & 1990 & \\
\hline 12 & The Pavilions, Bali & 0,70 & 30 & 16 & 46 & 2000 & \\
\hline 13 & Alits Beach Bungalow & 2,00 & 38 & 72 & 110 & 1972 & \\
\hline 14 & Mercure Resort Sanur & 4,03 & 147 & 70 & 217 & 1989 & \\
\hline 15 & Fairmont (Regent Bali Hotel) & 2,00 & 175 & 67 & 242 & 2013 & \\
\hline 16 & The Graha Cakra Bali & 1,00 & 35 & 12 & 47 & 2004 & \\
\hline 17 & Segara Village & 5,00 & 45 & 15 & 60 & 1957 & \\
\hline 18 & Abian Srama Hotel \& Spa & 0,40 & 26 & 14 & 40 & 1978 & \\
\hline 19 & Semawang Beach & 0,06 & 3 & 3 & 6 & 1988 & \\
\hline 20 & Inna Grand Bali Beach & 41,7 & 408 & 74 & 482 & 1966 & \\
\hline 21 & Puri Santrian & 3,02 & 395 & 92 & 487 & 1985 & \\
\hline 22 & Sanur Beach & 7,03 & 308 & 99 & 407 & 1974 & \\
\hline \multirow[t]{3}{*}{23} & La Taverna & 1,01 & 29 & 21 & 50 & 1976 & \\
\hline & Jumlah & 84,42 & 2542 & 853 & 3.395 & - & \\
\hline & Rata-rata & 3,67 & 111 & 37 & 148 & - & \\
\hline
\end{tabular}

Tabel 2 menunjukkan bahwa rata-rata luas hotel di Kawasan Pariwisata Sanur (KPS) adalah 3,67 ha. Kawasan hotel yang terluas adalah 41,7 ha, dan tersempit adalah 0,05 ha. Hal itu berarti bahwa kesenjangan luas areal dari hotel-hotel di KPS ternyata sangat tinggi. Tampaknya, hotel yang dibangun pada saat sektor pariwisata mulai dikembangkan di Bali secara besar-besaran, yakni pada tahun 1970-an, umumnya mendapat areal yang sangat luas. Misalnya hotel Grand Bali Beach, dan Hotel Segara Village. Selanjutnya, karena sektor pariwisata terus berkembang di Bali, termasuk di KPS, maka harga lahan terus semakin mahal. Dengan demikian pihak investor tampaknya tidak lagi mampu membeli lahan yang luas. Bahkan ada hotel di KPS yang luasnya hanya 0,05-0,06 ha. Misalnya, Hotel Sativa Sanur Cottages dan Hotel Semawang Beach.

Jumlah karyawan laki-laki lebih tinggi dari jumlah karyawan perempuan. Di KPS, jumlah karyawan laki-laki rata-rata 111 orang (75\%) dan jumlah karyawan perempuan 37 orang (25\%). Hal itu disebabkan karena pekerjaan di hotel umumnya adalah pekerjaan yang berat dan banyak terlama beroperasi adalah Hotel Sindhu Beach dan Hotel Segara Village, masing-masing tahun 1956 dan tahun 1957. Hotel yang terbaru beroperasi adalah Hotel The Graha Cakra Bali, yakni tahun 2004.

\subsection{Pengelolaan Lingkungan Berbasis THK di Kawasan Pariwisata Sanur}

Pengelolaan lingkungan, tidak hanya merupakan lingkungan fisik, tetapi juga termasuk lingkungan sosial-budaya (Suarna, 2007). Dalam kaitan itulah maka penelitian tentang lingkungan di kawasan hotel, harus dilaksanakan, dengan tidak hanya untuk memahami lingkungan fisik (palemahan) saja. Perlu juga memahami berbagai hal yang berkait dengan lingkungan manusia (pawongan), dan yang berkait dengan lingkungan spiritual (parhyangan). Hal itu disebabkan karena hotel menampung para tamu (manusia) yang memiliki karakter yang berbeda, namun mereka memerlukan ketenangan dan harmoni dalam kehidupannya. Kalau hotel telah menerapkan THK dengan baik, maka outputnya akan terjadi harmoni di hotel ybs. Baik harmoni di kalangan internal, dan juga harmoni dengan kalangan eksternalnya. 
Dengan adanya harmoni, maka keberlanjutan eksistensi hotel di kawasan itu akan lebih terjamin. Sebab tidak mungkin wisatawan akan mau menginap di sebuah kawasan yang penuh dengan konflik, dan tidak harmoni di internal dan dengan kalangan eksternalnya. Harmoni adalah suatu keadaan yang bisa menyebabkan suatu komunitas merasa nyaman di sebuah kawasan tertentu. Tidak ada konflik di kalangan internal hotel (antar karyawan, atau antar karyawan dengan pihak managemen), dan juga tidak ada konflik antara pihak hotel dengan masyarakat di sekitarnya. Adapun kasusnya adalah pada hotel yang dibangun di kawasan Tanah Lot, Tabanan. Karena proses pengembangan kawasan itu mengandung konflik, maka sejak dibangunnya hotel di kawasan tersebut, selalu terjadi konflik antara pihak hotel dengan masyarakat sekitar, yang merasa tidak puas dengan ganti rugi lahannya. Akibatnya, wisatawan yang menginap di kawasan itupun tidak bisa maksimal.

Seperti diketahui bahwa Kawasan Pariwisata Sanur (KPS) adalah merupakan kawasan pariwisata tertua dibandingkan dengan perkembangan kawasan pariwisata lainnya di Bali, misalnya Kuta, dan Nusa Dua. Oleh karenanya, diharapkan pihak hotel di KPS telah mampu mengembangkan penerapan konsep THK dalam pengelolaan lingkungannya. Adapun penerapan THK dalam pengelolaan lingkungan hotel di KPS, terlihat lebih rinci pada Tabel 3.

Tabel 3. menunjukkan bahwa pada penerapan THK dalam pengelolaan lingkungan di Kawasan
Pariwisata Sanur (KPS) termasuk dalam kategori : Sangat Baik, dengan skor 86,87\%. Hal ini mungkin disebabkan karena kawasan Sanur sudah sejak lama dikembangkan sebagai kawasan pariwisata. Bahkan Hotel Segara Village termasuk pembangunan hotel yang pertama di Bali. Dengan demikian kesadaran tentang peranan lingkungan yang sangat penting artinya dalam perkembangan pariwisata, telah tertanam dengan baik. Pihak wisatawan sudah semakin kritis memilih tempat penginapan. Mereka sering memilih hotel yang telah memiliki sertifikat yang berkait dengan lingkungan. Misalnya, sertifikat Green Globe, THK Awards, dll. Oleh karenanya, pihak hotel tentu saja harus mengantisipasi permasalahan itu, dengan secara sungguh-sungguh memperhatikan masalah lingkungannya. Hal ini dibuktikan dengan adanya pemanfaatan dana CSR untuk pelesarian lingkungan dan pemberdayaan masyarakat. Di kawasan Sanur, dana CSR pihak hotel dikelola pemanfaatannya oleh Yayasan Desa Sanur.

Berkait dengan eksistensi elemen THK tsb, maka berikut ini akan diuraikan penerapan ketiga elemen dalam THK itu, sebagai berikut.

\section{Pengelolaan lingkungan elemen parhyangan}

Adapun berbagai indikator yang diukur dalam elemen parhyangan adalah : (i) adanya pura di hotel; (ii) pengelolaan pura; (iii) pelaksanaan odalan di pura; (iv) pemeliharaan pura; (v) pelaksanaan ceramah

Tabel 3. Nilai Skor Rata-rata Implementasi Tri Hita Karana di Kawasan Pariwisata Sanur

\begin{tabular}{|c|c|c|c|c|}
\hline No & Variabel & Indikator & Nilai skor (\%) & Ket \\
\hline \multirow[t]{3}{*}{1} & 1. Parhyangan & $\begin{array}{l}\text { 1.1.Keberadaan pura di hotel } \\
\text { 1.2.Pengelolaan pura } \\
\text { 1.3. Pelaksanaan odalan di pura } \\
\text { 1.4.Pemeliharaan pura } \\
\text { 1.5.Pelaksanaan ceramah agama } \\
\text { 1.6.Bantuan kepada pura sekitar hotel }\end{array}$ & $\begin{array}{l}95,65 \\
95,65 \\
96,52 \\
94,78 \\
60 \\
78,26\end{array}$ & \\
\hline & Jumlah & & 520,87 & \\
\hline & Rata-rata & & 86,81 & \\
\hline \multirow[t]{6}{*}{2} & \multirow[t]{4}{*}{ 2.Pawongan } & 2.1.Ada harmoni antara pihak managemen dan pihak karyawan & 100 & \\
\hline & & 2.2.Ada tidaknya perjanjian kerja(PKB) & 94,78 & \\
\hline & & 2.3.Harmoni antara pihak hotel dengan masyarakat sekitarnya & 100 & \\
\hline & & 2.4.Jumlah karyawan sebagai pendukung budaya lokal (Bali) & 74,78 & \\
\hline & Jumlah & & 380,59 & \\
\hline & Rata-rata & & 90,15 & \\
\hline \multirow[t]{12}{*}{3} & \multirow[t]{9}{*}{ 3.Palemahan } & 3.1.Ruang Terbuka Hijau (RTH) & 91,30 & \\
\hline & & 3.2.Taman di kawasan hotel & 93,91 & \\
\hline & & 3.3.Pengelolaan air limbah & 87,83 & \\
\hline & & 3.4.Pengelolaan sampah & 87,83 & \\
\hline & & 3.5.Pengelolaan emisi & 80,87 & \\
\hline & & 3.6.Pengelolaan lingkungan & 87,83 & \\
\hline & & 3.7.Pengelolaan Bahan Berbahaya Beracun(B3) & 63,48 & \\
\hline & & 3.8.Bangunan ciri khas Bali & 87,83 & \\
\hline & & 3.9.Pemanfaatan CSR untuk kegiatan penghijauan & 74,78 & \\
\hline & \multicolumn{2}{|r|}{ (1) } & 755,65 & \\
\hline & \multicolumn{2}{|l|}{ Rata-rata } & 83,96 & \\
\hline & \multicolumn{2}{|c|}{ Skor rata-rata penerapan THK } & 86,97 & \\
\hline
\end{tabular}


agama; dan (v) bantuan kepada pura di sekitar hotel. Pencapaian skor rata-rata untuk elemen parhyangan adalah 86,81\% dan termasuk kategori : Sangat Baik. Adapun nilai skor tertinggi untuk elemen parhyangan adalah untuk indikator : pelaksanaan odalan di pura di hotel, dengan skor 96,52\% (sangat baik). Sedangkan skor terendah adalah untuk indikator : pelaksanaan ceramah agama, dengan skor 60\% (cukup). Berdasarkan skor-skor di atas, tampaknya pihak hotel sangat disiplin dalam melaksanakan odalan pada pura di hotel. Pihak hotel tidak mau ambil resiko untuk tidak melaksanakan odalan di hotel, karena melaksanakan odalan di pura bagi masyarakat Bali adalah sebuah keharusan. Kalau tidak, meraka akan merasa berdosa dan bisa juga akan jatuh sakit. Hal ini adalah tindakan yang rasional. Karena pura adalah salah satu lambang kebudayaan Bali. Eksistensi pura juga didukung dengan sangat fanatik oleh masyarakat. Artinya, kalau sampai ada pihak hotel yang tidak mau mengadakan odalan di pura, maka karyawan yang beragama Hindu akan protes dan bisa terjadi konflik. Kalau hal itu sampai terjadi, maka mungkin saja keamanan dan kenyamanan hotel itu akan terganggu.

Nilai skor untuk pelaksanaan ceramah agama di hotel skor-nya dalam kategori Cukup (60\%). Hal ini bermakna bahwa tampaknya hotel tidak begitu hirau dengan kegiatan ceramah agama di hotel. Dalam hal ini tampaknya pihak managemen tidak mau repot dengan aktivitas ceramah agama tsb. Hal ini sekaligus menunjukkan perhatian pihak manajemen terhadap eksistensi pura, yang seharusnya diisi dengan ceramah-ceramah agama. Bagi daerah Bali, eksistensi pura adalah hal yang sangat penting. Karena menjadi lambang dari kebudayaan Bali. Tanpa ada pura, maka tidak akan ada kegiatan upacara. Selanjutnya tidak ada kebersamaan dalam aktivitas sosial untuk mendukung eksistensi pura tsb. Itulah sebabnya, masalah parhyangan menjadi hal yang sangat penting untuk diperhatikan oleh pihak hotel yang ada di Bali. Dalam hal ini ceramah agama sangat perlu untuk mengisi pemahaman agama bagi karyawan. Diharapkan dengan demikian, produktivitas karyawan justru akan semakin meningkat.

\section{Pengelolaan lingkungan elemen pawongan.}

Adapun berbagai indikator yang diukur dalam elemen pawongan adalah : (i) ada harmoni antara pihak managemen dan pihak karyawan; (ii) adatidaknya perjanjian kerja (PKB); (iii) harmoni antara pihak hotel dengan masyarakat sekitarnya; dan (iv) jumlah karyawan sebagai pendukung budaya lokal (Bali).

Skor rata-rata untuk elemen pawongan adalah sebesar 90,15\% (kategori Sangat Baik). Adapun skor tertinggi dicapai oleh indikator : harmoni pihak hotel dengan masyarakat di sekitarnya, serta harmoni antara pihak managemen dan karyawan, yakni dengan skor : 100\% (sangat baik). Sedangkan skor terendah dicapai oleh indikator : jumlah karyawan pendukung budaya lokal (Bali), yakni dengan skor : 74,78\% (Cukup). Berdasarkan perolehan skor di atas, dapat dikatakan bahwa pihak hotel tampaknya memang selalu ingin menjaga harmoni dengan masyarakat sekitarnya dan juga harmoni di kalangan internal. Pihak hotel tidak mau mengambil resiko untuk konflik dengan masyarakat sekitarnya. Bila hal itu terjadi, maka resiko yang akan diperoleh oleh pihak hotel akan sangat besar. Pihak hotel beresiko akan selalu diganggu oleh pihak masyarakat sekitarnya. Kalau hal itu terjadi, maka para wisatawan yang menginap di hotel tersebut akan terganggu. Selanjutnya pendapatan pihak hotel juga akan sangat terganggu. Untuk tujuan itu, pihak hotel setiap tahun selalu menyediakan dana untuk disumbangkan kepada masyarakat sekitarnya, sesuai proposal kegiatan yang diajukan. Beberapa hotel yang besar, pihak manajemen bahkan ada yang menunjuk tenaga khusus, yang bertugas untuk melakukan komunikasi dengan pemuka masyarakat di sekitarnya. Kadang-kadang mereka mengundang para pemuka masyarakat untuk hadir dalam kegiatan di hotel. Tujuannya adalah agar selalu terjadi komunikasi sosial yang kondusif antara pihak hotel dengan pihak masyarakat sekitarnya.

Karyawan pendukung budaya lokal (Bali) skor yang dicapai termasuk kategori : cukup. Hal ini menunjukkan bahwa pihak hotel tidak bisa dihindari untuk harus merekrut tenaga dari pihak luar Bali, karena hotel memerlukan tenaga profesional. Khususnya untuk bidang-bidang tertentu, misalnya pada bidang yang berkait dengan kelistrikan, teknologi informasi, makanan/minuman, dll. Namun diharapkan pihak hotel lebih memprioritaskan penerimaan karyawan dari tenaga lokal, untuk menghindari friksi di masa depan.

\section{Pengelolaan lingkungan elemen palemahan.}

Adapun berbagai indikator yang diukur dalam elemen palemahan adalah : (i) keberadaan Ruang Terbuka Hijau (RTH); (ii) taman di kawasan hotel; (iii) pengelolaan air limbah; (iv) pengelolaan sampah; (v) pengelolaan emisi; (vi) pengelolaan lingkungan; (vii) pengelolaan Bahan Berbahaya Beracun (B3); (viii) bangunan dengan ciri khas Bali; dan (ix) pemanfaatan CSR untuk kegiatan penghijauan.

Bahwa skor rata-rata untuk elemen palemahan adalah sebesar 74,78\% (Baik). Adapun skor tertinggi dicapai oleh indikator : keadaan taman di kawasan hotel, dengan skor : 93,91\% (Sangat Baik). Sedangkan skor terjelek dicapai oleh indikator : pengelolaan bahana berbahaya beracun/B3, yakni dengan skor : 63,48 \% (Cukup). Dengan melihat data tersebut dapat 
dikatakan bahwa, adalah logis kalau pihak hotel mengutamakan penataan tanam di hotel sebagai hal yang penting dan diutamakan, karena menyangkut citra hotel kepada tamu-tamunya secara langsung di kawasan hotelnya. Namun sangat disayangkan ternyata kegiatan yang berkait dengan pengelolaan B3 kategorinya adalah : Cukup. Untuk itu diperlukan pendampingan yang intensif pada pihak hotel yang ada di Kawasan Pariwisata Sanur, agar lebih memperhatikan masalah lingkungan di sekitarnya, khususnya berkait dengan pembuangan limbah (B3). Hal ini penting, agar tidak membahayakan masyarakat sekitarnya, yang mungkin justru sama sekali tidak menikmati hasil dari sektor pariwisata.

\subsection{Kriteria dan Implementasi Tri Hita Karana pada Masing-Masing Hotel}

Di samping ditemukan rata-rata skor implementasi Tri Hita Karana (THK) di Kawasan Pariwisata Sanur, tampaknya diperlukan juga mengetahui implementasi THK pada masing-masing hotel di kawasan tsb. Hal itu penting, agar diperoleh gambaran tentang bagaimana pihak hotel mampu mengimplementasikan THK, yang telah menjadi Visi Pembangunan Bali. Selama ini yang telah terbukti mengimplementasikan THK dalam kehidupan sosialnya adalah sistem subak dan juga desa pakraman (Windia dan Dewi, 2011). Pihak hotel yang bergerak di sektor jasa, khususnya di Kawasan Pariwisata Sanur, juga sangat perlu diketahui implementasi THK tsb. (Tabel 4.).
Berkait dengan kriteria penerapan THK, dapat dilihat dari nilai skor penerapan THK secara keseluruhan, dan juga nilai skor masing-masing elemen THK (Parhyangan, Pawongan dan Palemahan). Kriteria penerapan THK yang Baik adalah kalau penerapan THK secara keseluruhan minimal dalam kategori Baik, dan juga penerapan masing-masing elemen THK (Parhyangan, Pawongan, Palemahan), harus juga minimal dalam kategori Baik.

Tabel 4. menunjukkan bahwa dari 23 hotel yang diteliti, satu hotel (4,35\%) penerapan THK-nya dalam kategori Cukup, enam hotel (26,09\%) kategori Baik, dan 16 hotel (69,56\%) kategori Sangat Baik. Secara umum, penerapan THK pada hotel-hotel di Kawasan Pariwisata Sanur, adalah baik. Kategori hotel dengan predikat: Sangat Baik, Baik, Cukup/Sedang, Tidak Baik, dan Sangat Tidak Baik, sesuai dengan kategori pada Tabel 1.

Melalui bahasan di atas, maka dari penelitian ini dapat diajukan kriteria bahwa hotel dapat dianggap penerapan THK-nya Baik, kalau penerapan masing-masing elemen THK dan juga penerapan THK secara keseluruhan, adalah minimal Baik. Sebab, mungkin saja terjadi, bahwa penerapan pada salah satu elemen THK adalah : Cukup/Sedang, Tidak Baik, atau Sangat Tidak Baik. Namun bisa terjadi, penerapan THK secara keseluruhan adalah : Baik. Dalam kasus ini, penerapan THK pada hotel yang bersangkutan, tidak bisa disebut Baik. Hal itu disebabkan, karena pada dasarnya THK adalah

Tabel 4. Implenentasai Tri Hita Karana pada Masing-Masing Hotel.

\begin{tabular}{|c|c|c|c|c|c|c|}
\hline \multirow{2}{*}{ No. } & \multirow{2}{*}{ Nama Hotel } & \multicolumn{3}{|c|}{ Rata-rata skor implementasi Elemen THK (\%) } & \multirow{2}{*}{$\begin{array}{l}\text { Rata-rata } \\
\text { Implemntasi } \\
\text { THK(\%) }\end{array}$} & \multirow[t]{2}{*}{ Ket } \\
\hline & & Parhyangan & Pawongan & Palemahan & & \\
\hline 1. & Inna Sindhu Beach & 96,67 & 100 & 86,67 & 94,40 & Sangat Baik \\
\hline 2 & Tanjung Sari & 96,67 & 95,00 & 88,89 & 93,50 & Sangat Baik \\
\hline 3 & Tamu Kami & 96,67 & 100 & 91,11 & 95,90 & Sangat Baik \\
\hline 4 & Gazebo & 63,33 & 80,00 & 53,33 & 65,60 & Cukup \\
\hline 5 & Besakih Beach & 76,67 & 95,00 & 80,00 & 83,90 & Baik \\
\hline 6 & Sanur Paradise Plaza Hotel \& Suites & 96,67 & 100 & 100 & 98,9 & Sangat Baik \\
\hline 7 & Diwangkara Holiday Villa & 83,33 & 100 & 88,89 & 87,4 & Sangat Baik \\
\hline 8 & Griya Santrian & 96,67 & 95,00 & 91,11 & 94,30 & Sangat Baik \\
\hline 9 & Peneda View Hotel & 70,00 & 80,00 & 71,11 & 73,70 & Baik \\
\hline 10 & Puri Dalem & 96,67 & 95 & 82,22 & 91,3 & Sangat Baik \\
\hline 11 & Sativa Sanur Cottages & 96,67 & 90,00 & 100 & 95,6 & Sangat Baik \\
\hline 12 & The Pavilions, Bali & 66,67 & 90,00 & 80,00 & 78,90 & Baik \\
\hline 13 & Alits Beach Bungalow & 83,33 & 85,00 & 77,78 & 82,00 & Baik \\
\hline 14 & Mercure Resort Sanur & 83,33 & 90,00 & 95,56 & 89,6 & Sangat Baik \\
\hline 15 & Fairmont (Regent Bali Hotel) & 80,00 & 95,00 & 77,78 & 84,3 & Sangat Baik \\
\hline 16 & The Graha Cakra Bali & 83,33 & 90,00 & 66,67 & 80,00 & Baik \\
\hline 17 & Segara Village & 100 & 95,00 & 97,78 & 97,60 & Sangat Baik \\
\hline 18 & Abian Srama Hotel \& Spa & 83,33 & 90,00 & 82,22 & 85,20 & Sangat Baik \\
\hline 19 & Semawang Beach & 66,67 & 100 & 65,22 & 76,30 & Baik \\
\hline 20 & Inna Grand Bali Beach & 100 & 95,00 & 100 & 98,30 & Sangat Baik \\
\hline 21 & Puri Santrian & 100 & 90,00 & 100 & 96,70 & Sangat Baik \\
\hline 22 & Sanur Beach & 80,00 & 95,00 & 86,67 & 87,20 & Sangat Baik \\
\hline 23 & La Taverna & 100 & 90,00 & 71,11 & 87,00 & Sangat Baik \\
\hline
\end{tabular}


sebuah sistem yang holistik. Oleh karenanya, kriteria penerapan THK dapat disebut : Baik, kalau semua elemen THK penerapannya dalam kategori minimal Baik, dan sekaligus penerapan THK secara keseluruhan, minimal Baik.

Adapun hotel di Kawasan Pariwisata Sanur, yang skor penerapan THK-nya paling tinggi adalah Sanur Paradise Plaza Hotel and Suites (98,9\%), dengan kategori Sangat Baik. Sedangkan hotel yang skor penerapan THK-nya paling rendah adalah Hotel Gazebo (65,6\%), dengan kategori Cukup. Umumnya skor yang penerapannya paling rendah adalah pada penerapan elemen palemahan.

\section{SIMPULAN DAN SARAN}

\subsection{Simpulan}

Berdasarkan uraian pada hasil dan pembahasan penelitian, dan juga dengan mengacu pada tujuan penelitian, maka dapat disimpulkan sebagai berikut.

1. Kriteria penerapan THK, terdiri atas elemen Parhyangan, Pawongan, dan Palemahan. Penerapan THK disebutkan dalam kriteria : Baik, kalau skor penerapan THK secara keseluruhan, minimal dalam kategori Baik, dan penerapan semua elemen THK, juga harus minimal dalam kategori Baik. Hotel di Kawasan Pariwisata Sanur dengan skor penerapan THK yang tertinggi adalah Sanur Paradise Plaza Hotel and Suites, dengan skor penerapan THK 98,9\%, ber-kriteria Sangat Baik. Sedangkan hotel dengan penerapan THK terendah adalah Hotel Gazebo, dengan skor penerapan THK sebesar 65,6\%, ber-kriteria Cukup.

2. Tingkat penerapan THK pada hotel-hotel di Kawasan Pariwisata Sanur adalah sebesar $86,97 \%$ (sangat baik). Sementara itu penerapan per-elemen THK dapat dilihat bahwa tingkat penerapan elemen parhyangan adalah 86,81\% (sangat baik), elemen pawongan adalah 90,15\% (sangat baik), dan elemen palemahan adalah $74,78 \%$ (baik).

\subsection{Saran}

Berdasarkan uraian pada simpulan, dapat disarankan sebagai berikut.

1. Hotel yang penerapan THK, dengan kriteria belum baik, perlu melakukan berbagai kegiatan yang berkait dengan implementasi THK, agar kategori-nya dapat meningkat. Kegiatan yang dapat dilakukan, sesuai dengan berbagai indikator pada elemen-elemen Parhyangan, Pawongan, dan Palemahan tsb.

2. Penerapan THK dalam kategori skor belum Baik, masih ditemukan pada elemen THK pada beberapa hotel sampel. Untuk itu perlu terus dikembangkan agar semua elemen THK pada hotel di Kawasan Pariwisata Sanur, dapat masuk dalam kategori minimal Baik.

3. Indikator hotel yang berbasis THK kiranya dapat terus dikembangkan lebih lanjut, dan terus diuji pada kawasan pariwisata yang lebih luas, sehingga dengan demikian akan didapatkan suatu indikator yang baku di masa yang akan datang. Dengan demikian akan dapat dijadikan sebagai pegangan pokok dalam menilai penerapan THK pada hotel di Bali, dan mungkin juga di Indonesia.

\section{DAFTAR PUSTAKA}

Amalia, G.R. 2013. Peran stakeholder dalam implementasi kebijakan pengendalian pencemaran air sungai di Kota Sorabaya, Media Jurnal Politik Muda, 2 (2) : 65-71.

Antara, I.M. 2010. Bahan Ajar Metodelogi Penelitian Sosek, Program Studi Agribisnis, Unud, Denpasar.

Azwar, S. 1997. Realibilitas dan Validitas, Pustaka Pelajar, Yogyakarta.

Bappeda Prov. Bali. 2013. Bali dalam angka tahun 2012, Denpasar.

Fardiaz, S. 1992. Polusi air dan udara, Penerbit Kanisius, Yogyakarta.

Subhi, M. 2011. "Perijinan pembuangan limbah cair kegiatan industry dalam hubungannya dengan pengendalian pencemaran air (Studi di Kab. Ketapang), Kalimantan Barat" (tesis), Kalimantan Barat: Universitas Tanjungpura.

Suarna, W. 2007. Etika Lingkungan, dalam Kearifan lokal dalam pengelolaan lingkungan hidup (ed: AAGR Dalem, IN Wardi, IW Suarna, dan IWS Adnyana), Denpasar, Penerbit Univ. Udayana, Denpasar.

Menparpostel. 1987. Surat Keputusan Nomor : Km/ HK103/MPPT/1987.

Dirjen Pariwisata.1978. Surat Keputusan Nomor : Kep-22/U/VI/ tahun 1978.

Undang-Undang No. 32 th 2009, tentang Pengelolaan Lingkungan Hidup.

Wibowo, M dan F.Andreani. 2013. Analisis peranan sistem manajemen limbah berdasarkan sertifikat eco-hotel di Sheraton Surabaya Hotel and Towers, Jurnal Hospitality dan Manajemen Jasa, 2 (1) : 48-54.

Windia, W. 2002. Transformasi sistem irigasi subak yang berlandaskan Tri Hita Karana, (disertasi), Yogyakarta, UGM.

Windia, W. dan R.K. Dewi. 2011. Analisis bisnis yang berlandaskan Tri Hita Karana, Denpasar, Udayana University Press. 